\title{
End-users' expectations and experiences with the decision support system MOIRA-PLUS
}

\author{
E. GALLEGO ${ }^{1}$, L. MONTE ${ }^{2}$, D. HOFMAN ${ }^{3}$
}

\begin{abstract}
MOIRA-PLUS is a decision support system (DSS) designed to address the mid and long-term issues after nuclear accidents causing the contamination of freshwater bodies and catchments with radionuclides. It is designed to allow for a reliable assessment of the long-term evolution of the radiological situation and of possible alternative rehabilitation strategies, including an objective evaluation of their social, economic and ecological impacts in a rational and comprehensive manner. MOIRA also features a decision analysis methodology, making use of multi-attribute analysis, which can take into account the preferences and needs of different types of stakeholders. The main functions and elements of the MOIRA-PLUS DSS are described summarily, together with the conclusions from end-user's experiences with the system. MOIRA-PLUS has proven to be a mature system, user friendly and relatively easy to set up. It can help to reassure the public by enabling a realistic evaluation of the complete impacts of possible recovery strategies. However, the users also identified possibilities for further improvement of the DSS.
\end{abstract}

\section{Introduction}

In the mid-long-term after a nuclear accident, the contamination of freshwater systems with radionuclides may affect drinking water sources, fish and other aquatic foodstuffs, irrigation supplies and people's exposure during recreational activities. Consequently, it can create significant public concern, even though dose assessment may in many situations indicate lesser importance than for other exposure sources, as clearly experienced in the aftermath of the Chernobyl accident.

MOIRA ("MOdel-based computerised system for management support to Identify optimal remedial strategies for Restoring radionuclide contaminated Aquatic ecosystems and drainage areas") is a decision support system (DSS) for analysing mid-long-term management strategies applicable to freshwater systems contaminated with long-lived ${ }^{137} \mathrm{Cs}$ and ${ }^{90} \mathrm{Sr}$. It was designed to allow for a

\footnotetext{
1 Nuclear Engineering Department, E.T.S. Ing. Industriales, Universidad Politécnica de Madrid, José Gutiérrez Abascal 2, 28006 Madrid, Spain, e-mail: eduardo.gallego@upm.es

2 ENEA, CR Casaccia, via P. Anguillarese, 301, CP 2400, 00100 Roma AD, Italy.

3 Consultant, Ö. Kyrkogatan 35, 61133 Nyköping, Sweden.
} 
reliable assessment of the long-term evolution of the radiological situation and of possible alternative management strategies, including an evaluation of their social, economic and ecological impacts in a rational and comprehensive manner. It was developed and tested during the 4th Euratom Framework Research Programme (EFRP) (Monte et al., 2000; Monte et al., 2002) and subject to additional testing and comparisons with other models inside the EVANET-HYDRA network of the 5th EFRP (Monte et al., 2005). The latest version, MOIRA-PLUS ${ }^{\odot}$, incorporates many features derived from user's experience and feedback (Monte et al., 2009). It is a software tool to run quantitative evaluations of the fate of radionuclides deposited in the catchments or directly released to lakes and rivers, simulating the consequences of selected interventions, calculating costs and analysing benefits.

Evaluation of the end-users' practical experience with MOIRA has been performed both in the frame of the EVANET-HYDRA network (Monte et al., 2005) and EURANOS project (Raskob, 2007) through demonstrations and practical exercises with the participation of both software developers and potential users and tests of application to specific scenarios.

The main aim of this work is to describe, briefly, the main features of MOIRAPLUS and to discuss the above mentioned end-users' experiences.

\section{Functions and elements of MOIRA-PLUS DSS}

The present section is aimed at illustrating, briefly, the main principles, features and functionalities of MOIRA-PLUS which are copiously described in the scientific literature (Gallego and Jiménez, 2000; Hofman, 2005; Håkanson and Sazykina, 2001; Monte et al., 2009).

Each comprehensive DSS can be classified according to their main features and aims at four levels (Ahlbrecht et al., 1997; Schulte et al., 2002), starting with the presentation of radiological data and related geographical / demographical information (level 0), the analysis and prediction of current and future radiological situation (level 1), the simulation of potential countermeasures, determining their feasibility and quantifying their benefits and disadvantages (level 2); and, finally, performing an evaluation and ranking of alternative countermeasure strategies, by assessing the balance of their advantages (dose reduction, environmental improvement) and disadvantages (economic, ecological and social impacts, etc.) accounting for the judgements and preferences of the decision makers (level 3).

MOIRA-PLUS accomplishes the objectives of all levels. The DSS is based on: - validated models for predicting the time behaviour of contaminants $\left({ }^{137} \mathrm{Cs}\right.$ and

${ }^{90} \mathrm{Sr}$ ) in lakes, rivers and drainage areas (Håkanson and Monte, 2003). These models simulate: (a) the time behaviour of the hydrological, morphologic and 
environmental quantities and of the migration parameters of contaminants through the water ecosystems; (b) the migration of radionuclides from the catchment to the aquatic system, through the abiotic components of the aquatic system and from the abiotic components to fish species; (c) the effects of selected countermeasures to reduce the contamination levels of the water bodies. These models have been tested and improved also accounting for the evaluations of state-of-the-art techniques for modelling the processes of migration of radionuclides through the fresh water environment (Monte et al., 2003, 2004, 2005);

- models to estimate the radiological doses to man and biota (fish) and to assess the dose reduction obtained by implementing countermeasures affecting the direct human exposure to contaminated elements (Gallego and Jiménez, 2000);

- in lakes, a Lake Ecosystem Index (LEI) model to assess the impact of countermeasures on the lake ecological quality (Håkanson et al., 2000);

- a conceptually simple micro-economic approach to assess the economic cost of the different kind of countermeasures implemented in the MOIRA sub-models, which gives the user a full control on the basic data needed for the calculations (unitary costs);

- methodologies based on multi-attribute analysis (MAA) techniques for ranking the different feasible interventions accounting for the above-mentioned impacts (Ríos-Insúa et al., 2006);

- software components implementing the above models and methodologies, combining all the components into one integrated DSS system and supporting the system with a user- friendly interface (Hofman, 2004);

- data storage and analysis tools (Geographical Information System and data bases) (Hofman, 2004).

\subsection{Countermeasures}

In the event of radioactive contamination of aquatic ecosystems and their drainage areas there are a number of available countermeasure options ranging from specific chemical treatment of water bodies to bans on fish ingestion or on the use of water for crop irrigation. The potential actions can be broadly grouped into four main categories, chemical, biological, physical and social. A DSS like MOIRA can be of great help to optimise a decision by accounting for single options or for suitable combinations of different remedial actions. Table I shows a list of countermeasures whose effects can be assessed by MOIRA-PLUS (Monte et al., 2009). 
TABLE I

Countermeasures which can be considered in MOIRA-PLUS for aquatic ecosystems and their mode of action.

\begin{tabular}{|c|c|c|c|c|}
\hline Approach & Action & $\begin{array}{l}\text { Location of } \\
\text { action }\end{array}$ & Mode of action & $\begin{array}{l}\text { Experience, } \\
\text { models and data }\end{array}$ \\
\hline Chemical & Potash treatment & $\begin{array}{l}\text { Lakes, reservoirs, } \\
\text { rivers }\end{array}$ & Chemical "dilution" & $\begin{array}{l}\text { Some experience and data } \\
\text { for lakes. Models } \\
\text { available. }\end{array}$ \\
\hline Chemical & $\begin{array}{l}\text { Direct liming / } \\
\text { catchment liming }\end{array}$ & $\begin{array}{l}\text { Lakes, reservoirs, } \\
\text { rivers }\end{array}$ & $\begin{array}{l}\text { Changes } \mathrm{pH} \text {, which } \\
\text { influences for example } \\
\text { biouptake }\end{array}$ & $\begin{array}{l}\text { Considerable experience } \\
\text { in relation to acidification. } \\
\text { Models available. }\end{array}$ \\
\hline Chemical & Fertilisation & $\begin{array}{l}\text { Lakes, reservoirs, } \\
\text { rivers }\end{array}$ & $\begin{array}{l}\text { Increases biomass, } \\
\text { "biological dilution" }\end{array}$ & $\begin{array}{l}\text { Considerable experience in } \\
\text { relation to eutrophication. } \\
\text { Models available. }\end{array}$ \\
\hline Physical & $\begin{array}{l}\text { Control water flow } \\
\text { through rate }\end{array}$ & $\begin{array}{l}\text { Lakes, reservoirs, } \\
\text { rivers }\end{array}$ & $\begin{array}{l}\text { Change water retention } \\
\text { time; open dams, fill } \\
\text { reservoir, etc. }\end{array}$ & $\begin{array}{l}\text { Site-specific. Limited } \\
\text { experience, limited } \\
\text { success. Models available. }\end{array}$ \\
\hline $\begin{array}{l}\text { Physico- } \\
\text { chemical }\end{array}$ & $\begin{array}{l}\text { Removal of } \\
\text { contaminated } \\
\text { sediments }\end{array}$ & $\begin{array}{l}\text { Lakes, reservoirs, } \\
\text { rivers }\end{array}$ & $\begin{array}{l}\text { Reduction in active } \\
\text { sediment layer and/or } \\
\text { direct exposure to man }\end{array}$ & $\begin{array}{l}\text { Little experience. Can be } \\
\text { modelled. }\end{array}$ \\
\hline $\begin{array}{l}\text { Physico- } \\
\text { chemical }\end{array}$ & Sediment traps & $\begin{array}{l}\text { Lakes, reservoirs, } \\
\text { rivers }\end{array}$ & $\begin{array}{l}\text { Collection of } \\
\text { radionuclides associated } \\
\text { with particles }\end{array}$ & $\begin{array}{l}\text { Tried after Chernobyl but } \\
\text { unsuccessful. Can be } \\
\text { modelled. }\end{array}$ \\
\hline $\begin{array}{l}\text { Physico- } \\
\text { chemical }\end{array}$ & $\begin{array}{l}\text { Removal of } \\
\text { contaminated snow } \\
\text { and ice }\end{array}$ & $\begin{array}{l}\text { Lakes, reservoirs, } \\
\text { catchments, } \\
\text { rivers }\end{array}$ & $\begin{array}{l}\text { Reduction in source term } \\
\text { and/or direct exposure to } \\
\text { man }\end{array}$ & $\begin{array}{l}\text { Site-specific. No } \\
\text { experience, but can be } \\
\text { modelled. }\end{array}$ \\
\hline $\begin{array}{l}\text { Physico- } \\
\text { chemical }\end{array}$ & $\begin{array}{l}\text { Treatment of drinking } \\
\text { water }\end{array}$ & $\begin{array}{l}\text { Lakes, reservoirs, } \\
\text { rivers }\end{array}$ & $\begin{array}{l}\text { Reduction in dose from } \\
\text { drinking water }\end{array}$ & $\begin{array}{l}\text { Some experience after } \\
\text { Chernobyl. Can be } \\
\text { modelled. }\end{array}$ \\
\hline $\begin{array}{l}\text { Chemical/ } \\
\text { Social }\end{array}$ & Food preparation & All ecosystems & $\begin{array}{l}\text { Reduction in dose } \\
\text { through food }\end{array}$ & $\begin{array}{l}\text { Some experience. Can be } \\
\text { very effective. }\end{array}$ \\
\hline Social & $\begin{array}{l}\text { Bans on fish } \\
\text { consumption }\end{array}$ & $\begin{array}{l}\text { Lakes, reservoirs, } \\
\text { rivers }\end{array}$ & $\begin{array}{l}\text { Reduction in dose } \\
\text { through food }\end{array}$ & $\begin{array}{l}\text { Some experience. Can be } \\
\text { effective. Models } \\
\text { available. }\end{array}$ \\
\hline Social & $\begin{array}{l}\text { Alternative drinking } \\
\text { water sources, e.g. } \\
\text { groundwater }\end{array}$ & $\begin{array}{l}\text { Lakes, reservoirs, } \\
\text { rivers }\end{array}$ & $\begin{array}{l}\text { Reduction in dose from } \\
\text { drinking water }\end{array}$ & $\begin{array}{l}\text { Site-specific. Some } \\
\text { experience. Effective. Can } \\
\text { be modelled. }\end{array}$ \\
\hline Social & $\begin{array}{l}\text { Irrigation bans/ } \\
\text { restrictions }\end{array}$ & $\begin{array}{l}\text { Lakes, reservoirs, } \\
\text { rivers }\end{array}$ & $\begin{array}{l}\text { Reduction of uptake in } \\
\text { crops }\end{array}$ & $\begin{array}{l}\text { Some experience; can be } \\
\text { effective. Can be modelled. }\end{array}$ \\
\hline Social & Restricted areas & All ecosystems & $\begin{array}{l}\text { Reduction in dose to } \\
\text { population }\end{array}$ & $\begin{array}{l}\text { Site-specific. Some } \\
\text { experience; can be } \\
\text { effective. Can be modelled. }\end{array}$ \\
\hline
\end{tabular}

\subsection{Evaluation of the ecological impact of countermeasures}

Remedial measures, by their nature may have a greater or smaller impact on ecosystem functioning. The main object of ecosystem impact assessment is to make management aware of the potential effects and dangers of a particular remedial action. 
The evaluation of the ecological impact of a countermeasure may be overwhelmingly difficult and would probably involve complicated ecosystem modelling and the application of life cycle analysis. Therefore, a more simple solution has been developed for the use in MOIRA.

MOIRA's LEI is a quantitative methodology to measure the ecological impact of countermeasures on aquatic ecosystems (Håkanson et al., 2000). LEI is a tool to give an account for the environmental (and not just radiological) consequences of chemical remedial measures (lake and wet land liming, potash treatment and lake fertilisation) carried out to reduce radionuclide levels in water, sediments and biota. The LEI has been developed to account for the ecological impact of countermeasures in a simple, rational manner from a radioecological perspective (Håkanson and Peters, 1995).

\subsection{Evaluation of the social impact of countermeasures and MAA}

In the process of identifying the optimal remedial strategies after a radioactive contamination of aquatic ecosystems, social and economic factors may be of considerable importance. Countermeasures are an obvious source of economic costs and, in many cases, can cause more or less serious societal repercussions, as well as affecting individuals. The evaluation of such impacts is always an important part of the decision-making process. In optimising intervention strategies one should include, obviously, health and safety and the tangible costs of protective actions, as well as other non-quantifiable factors such as reassurance, stress, and other societal values that should be taken into account by the decisionmaker. Normally, these non-quantifiable factors can only be considered in a qualitative manner, and this is possible by using techniques like the MAA implemented in MOIRA.

In the frame of the MAA evaluation of intervention strategies, the social impact is handled by two objectives: minimising the impact on health and on living conditions. Concerning "health impact", radiation and non-radiation effects are incorporated: the first are evaluated by assessing the dose to critical individuals and the collective dose; on the other hand, less specific stress-related effects that can result from the accident itself and from the application of countermeasures, are considered in a subjective, qualitative way. For "living restrictions", we take into consideration the impacts related with countermeasures affecting drinking water and water use by the food industry, the direct use of fish for food or its processing in the food industry (e.g., canned, smoked, salted, etc.), the use of water for irrigation of crops and the recreational uses of water bodies. For all these objectives, the attributes will be the number of persons, the area of crops or the amount of fish affected by restrictions and the duration of such restrictions. 


\subsection{The MOIRA-PLUS software}

When evaluating a scenario of environmental contamination with MOIRA-PLUS, the user performs in general the following steps:

- selection of the "target" object (lake, river, reservoirs) and definition of its sitespecific characteristics (if site specific data are not available, default data can be supplied);

- definition of the radionuclide contamination (time-dependent and, in the case of rivers, spatially distributed);

- definition of alternative countermeasure strategies, i.e. flexible combinations of the available countermeasures;

- running the sequence of models appropriate to the scenario;

- running the MAA module in order to rank alternative management strategies;

- producing a summary report containing information on source data, results and ranked management strategies.

MOIRA-PLUS is a user-friendly computer software system set in an environment based on PC and Windows ${ }^{\circledR}$. The software framework was developed using Microsoft Visual C++. The graphical user interface (GUI, see Fig. 1) has several tabs ("Site-specific data", "Case definition", "Strategies", "Results", "Optimal strategy", "Report") relevant to the steps of evaluating a scenario of environmental contamination enumerated above. Links to datasets are presented as icons located "under" the tabs (some icons are also combined in "folders", for example, "socioeconomic data", "environmental data", "no actions", "strategy X"). Results of the scenario evaluation are summarised in a report, which is automatically generated as an html file. MOIRA GUI combines Explorer-like style of data browsing with GIS-like features. If the studied object is a river then some datasets are connected to a specific river segment (for example "population data for segment 2", "runoff data for segment 1", "removal of contaminated sediments, segment 3") and are accessed using geographical map shown in GUI Map windows. MORA GUI uses MapInfo ${ }^{\circledR}$ Integrated Mapping technique which allows the visualisation of MapInfo maps in Map windows, but requires that MapInfo is installed on the same computer as MOIRA. However, GUI also provides alternative methods to access tables connected to specific river segments if MapInfo is not installed.

MOIRA GIS supports storing (in MapInfo format), retrieval and analysis of spatially distributed data used as initial values (which can be overwritten by the user) for the datasets containing site-specific information. Several GIS-based models (constructed in the environment of MapBasic) are applied to help the user in querying and analysis of these data to prepare site-specific datasets for the selected lake, reservoir or river. The user accesses MOIRA GIS data and invokes 


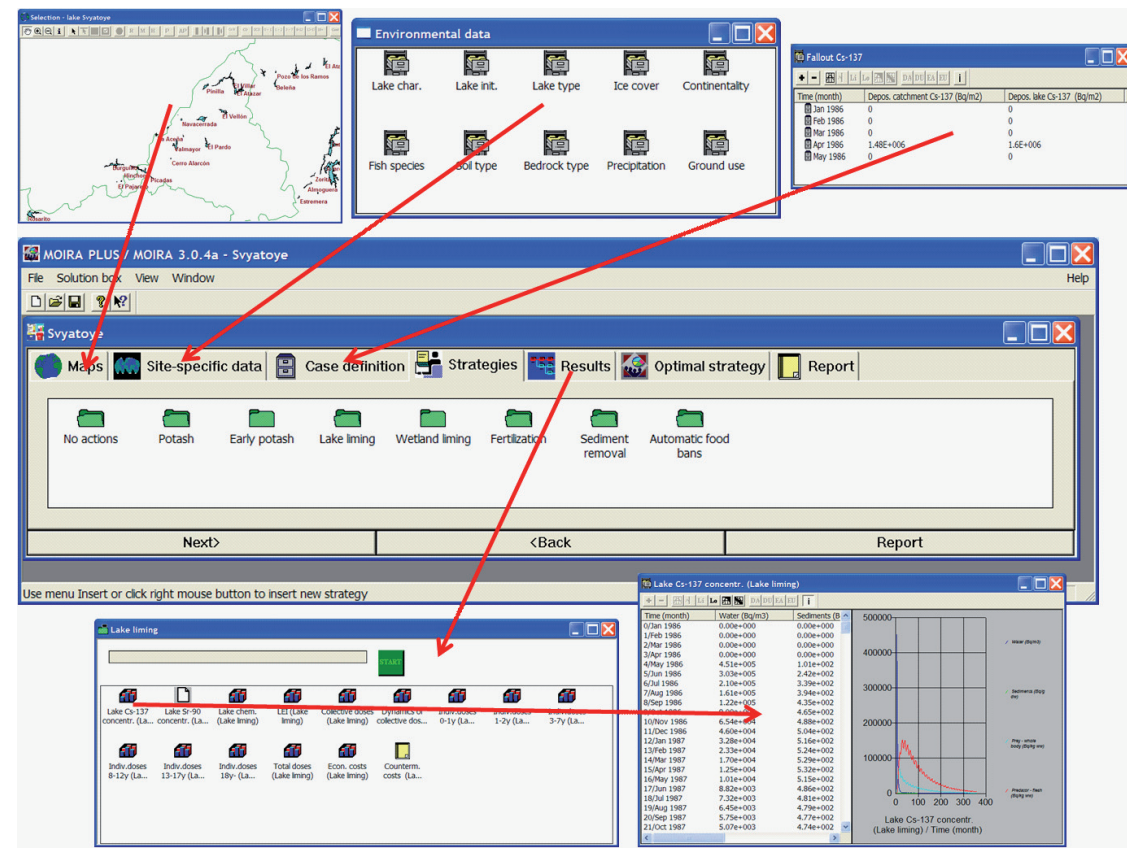

Figure 1 - Overall view of MOIRA-PLUS graphical user interface with a display of some of its main elements around: in the upper part, some of the elements necessary to define a case to be analysed; in the centre, the main window, with the alternative strategies being analysed; in the lower part, interactive display of results.

GIS models via GUI windows, similar to the ones used to select river segments. By default, MOIRA GIS contains detailed data for 30 lakes in Sweden, topology of the River Tevere (Italy), land use, population, fish species, bedrock and soil data for Western Europe. Default socioeconomic data (which are not spatially distributed in MOIRA) are stored in the reference data base RefDB. Both GIS and RefDB are easily customisable (Hofman et al., 2005).

It is desirable that the dependency of DSS on commercial software is reduced to a minimum in order to assure its wide usage and dissemination. To run MOIRA models it is necessary to install the software Powersim Constructor ${ }^{\circledR}$ Run-Time Version 2.51. However, in the frame of the EVANET-HYDRA project a certain number of licenses for this software were purchased for the users' community, although in future it would be useful to have a freely redistributable models "engine" in MOIRA. MOIRA also optionally requires the installation of MapInfo Professional for GIS data customisation and the reflection of geographical maps in the MOIRA GUI. Work to substitute MapInfo for freely distributed open source 


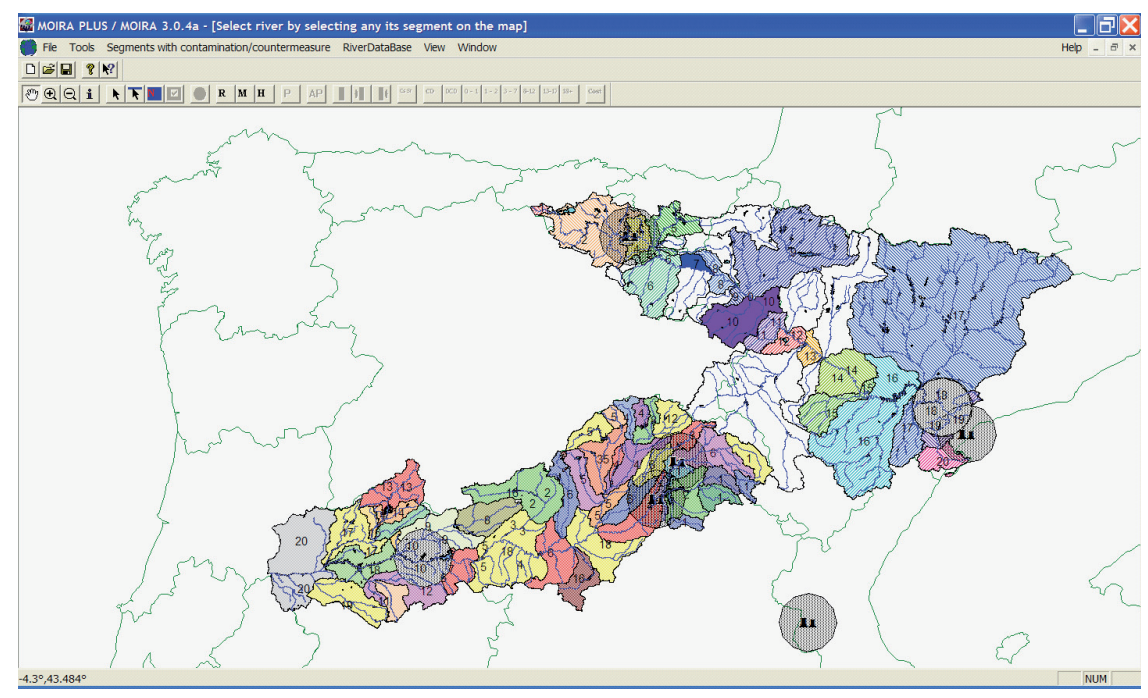

Figure 2 - An example of MOIRA-PLUS customisation: the Tagus and Ebro rivers in Spain.

GIS software is currently in progress. The MOIRA system is available free-ofcharge from the authors and a web site (http://user.tninet.se/fde729o/MOIRA) is maintained to provide support to users.

\section{End user's experience}

As we have previously noted, evaluation of the end-users' practical experience with MOIRA has been performed in the frame of the EVANET-HYDRA network (Monte et al., 2005) and of EURANOS project (Raskob, 2007).

In particular, within EURANOS the demonstration activities with MOIRA were aimed at checking the applicability of the system for the definition and the analysis of a variety of appropriate strategies for the long-term management of contaminated freshwater bodies, and the validity of the system as a tool in the decision making process able to incorporate inputs from different ranges of stakeholders. To reach these objectives, the demonstration project covered two levels of activities: on the one hand, MOIRA was installed in an operational emergency management centre and was customised with the corresponding local and regional characteristics and data (Fig. 2). This was performed at the Nuclear Safety Council (CSN) of Spain. An application exercise in two phases was conducted there for an assumed accident scenario involving significant contamination of freshwater bodies in Spain. 
Also, MOIRA was distributed to several EURANOS partners, who installed the system, tested it and evaluated its functionality, ease of usage, and results obtained. The participants in demonstration tests evaluated the long-term evolution of ${ }^{137} \mathrm{Cs}$ contamination in fish and water in the lake Kohzanovskoe (Bryansk region, Russia) for the post-Chernobyl period and compared it against empirical data. They also tested different intervention strategies based on the countermeasures that the system is able to simulate, and analysed them with the MAA module.

An obvious requirement from the end-users also having participated in the former EVANET-HYDRA project was to increase as much as possible the number of radionuclides considered in the DSS. As MOIRA focuses on the mid and longterm effects, only ${ }^{137} \mathrm{Cs}$ and ${ }^{90} \mathrm{Sr}$, two long-lived radionuclides of ecological importance for the freshwater environment, are considered. However, in principle, it is possible to apply the environmental migration models of MOIRA to any other radionuclide, provided that the values of certain migration parameters are supplied: the radioactive decay constant, the radionuclide transfer coefficient from water body catchments, the radionuclide bioaccumulation factors in prey and predatory fish species and the rate coefficients of some processes controlling the time behaviour of radionuclides in the abiotic and the biotic components of the environment (environmental decay of radionuclide concentration in water migrating from catchments, biological dynamics of radionuclide in fish, radionuclide interaction with sediment).

The applications have confirmed the possibility of rapid customisation of MOIRA data by the users. However, the functionality of MOIRA is limited to the definition of not more than 20 river branches and reaches. These branches and reaches can be combined to model complex river systems according to their shape features (tributaries of different levels and forks). End-users considered a detailed and accurate documentation describing how to implement such kinds of complex fresh water systems in the DSS of particular importance.

The exercise at CSN was a unique opportunity to test the capabilities of MOIRA DSS in a fully realistic environment, featuring the participation of organizations responsible for emergency management, local and regional stakeholders and international observers. The aim was to test and improve the ability of communicating and interacting between different cooperating agencies involved in the decision-making process following accidental events of radioactive contamination of water bodies. In particular, a simulation of the contamination resulting from a severe accident leading to releases of ${ }^{137} \mathrm{Cs}$ and ${ }^{90} \mathrm{Sr}$ in the basin of the Tagus River was performed (contamination at the regional scale). 
The whole exercise was successful and provided several useful lessons and conclusions (Gallego et al., 2009). Some of these concern technical issues relevant to the use of the DSS: the proper implementation of a DSS needs a great deal of background environmental and socio-economic information. Successful operational use may also require that such data are prepared in advance and maintained over time. Although definition of generic typical environments can be useful to get generic results, site specific peculiarities can be relevant to obtain representative results, which otherwise could be dismissed by local stakeholders and intervening agencies. The capacity to assess the economic cost of implementing countermeasures was considered as a very positive characteristic of MOIRA. However, base unit costs should be reviewed taking into account local specific information if available. The system should also have models to assess the dose to workers implementing countermeasures, at least those implying a higher contact with contaminated material, like sediments.

Other conclusions refer to organizational and preparedness aspects in response to radiological contamination events. The exercise unveiled the need for a better interface and understanding between agencies and stakeholders and demonstrated that the use of a user-friendly well structured DSS allows all participants to have a greater awareness of respective competencies and capacities by aiding cross-actor interactions and thus contributing towards a better common understanding of the important issues. This can help in achieving a greater consensus among the different participants in the decision making process in relation to the most appropriate actions for the management of the radiological consequences of a nuclear accident.

From the experience and comments of the participants in the customisation/application exercises, it can be concluded that MOIRA is considered rather useful by the end users as software support for the management of contaminated fresh water bodies, with unique features for assessing consequences and countermeasures for a radioactive deposition on the surface of aquatic systems. The software was found easy to install, to use and to understand. Adaptation to regional settings did not seem to be overly complicated. The GIS support with MapInfo Professional is very good, with the advantage of the easy customization but the disadvantage of high costs licence. Self-learning is possible, but users demand more complete documentation about the implemented models as well as to provide some reference default exercises both for lakes and rivers that could help them to learn and run properly MOIRA system, including the most useful choices and advices in solving different tasks (for instance, concerning the application of some countermeasures). They also appreciate a well working decision analysis tool, as it helps evaluating the options and gaining further insight. However, they found the current software 
(MAA) not well enough integrated and slightly complicated. In summary, MOIRA was considered a good and useful tool, with possibilities to improve.

Also, a new issue, "integration" became apparent. It was emphasised that the users would like to use MOIRA and other computerised decision support system like RODOS-HDM (Schulte et al., 2002) as complimentary DSS to perform shortterm and long-term assessment and countermeasure evaluation. Establishing an automated data exchange between these DSS can simplify decision making and data input procedures for the users of both systems.

\section{Conclusions}

MOIRA-PLUS make use of models that can be easily customised for the specific applications and also features a decision analysis methodology, making use of multi-attribute analysis (MAA) (Ríos-Insúa et al., 2006), which can take into account the preferences and needs of different types of stakeholders. Social and economic impacts are also incorporated into the MAA frame. In summary, MOIRA provides a quick insight in the effectiveness of countermeasures, avoiding the choice of inappropriate and expensive strategies.

MOIRA-PLUS has proven to be a mature system, user friendly and relatively easy to set up. It can help to reassure the public by enabling a realistic evaluation of the social, economic, and ecological impact of possible recovery strategies after a fresh water contamination in case of a nuclear accident. It clearly can aid crossagency interaction and thus better common understanding of all related issues. It could also assist in the identification of water bodies where higher levels of contamination might be expected and in the definition of sampling strategy.

Finally, by displaying a complete picture of the post-accident situation with regard to freshwater and management alternatives with their impacts, it helps to generate an aware consensus among the actors participating in the decision process concerning the management of the contaminated water bodies.

\section{REFERENCES}

Ahlbrecht M., Borodin R., Borzenko V., Ehrhardt J., French S., Shershakov V., Sohier A., Trakhtengerts E., Verbruggen A. (1997) Decision support issues in RODOS: the needs of decision makers, Radiat. Prot. Dosim. 73, 81-84.

Gallego E., Jiménez F. (2000), Radiation Dose and Countermeasure Model for a Decision Support System on Freshwater Ecosystems Contaminated with Radionuclides. In: $10^{\text {th }}$ International Congress of the International Radiation Protection Association (IRPA-10), Hiroshima, Japan, May 14-19, 2000, Available at http://www2000.irpa.net/irpa10/cdrom/00398.pdf.

Gallego E., Magán M., Cadierno J.P.G., Gil E., Monte L., Hofman D. (2009) Long-term management of contaminated freshwater bodies and catchments. Decision making exercise with the MOIRA system, Radioprotection 44, 683-688. 
Håkanson L., Peters R.H. (1995) Predictive Limnology, first edn. SPB Academic Publishing, Amsterdam, $464 \mathrm{p}$.

Håkanson L., Gallego E., Ríos-Insúa S. (2000) The application of the lake ecosystem index in multiattribute decision analysis in radioecology, J. Env. Radioact. 49, 319-344.

Håkanson L., Monte L. (2003) Radioactivity in lakes and rivers. In: Modelling Radioactivity in the Environment, (Scott, E.M., Ed.), pp.147-200. Elsevier, Oxford.

Håkanson L., Sazykina T. (2001) A blind test of the MOIRA lake model for radiocesium for Lake Uruskul, Russia, contaminated by fallout from the Kyshtym accident in 1957, J. Environ. Radioact. 54, 327-344.

Hofman D. (2004) MOIRA DSS - Architecture, model integration and user interface design. In: Complexity and Integrated Resources Management, Transactions of the 2nd Biennial Meeting of the International Environmental Modelling and Software Society, IEMSS, Manno, Switzerland. (Pahl-Wostl C., Schmidt S., Rizzoli A.E., Jakeman A.J., Eds.).

Hofman D. (2005) LIANA model integration system - architecture, user interface design and application in MOIRA DSS. In: Advance in Geosciences 4, Model integration and development of modular modelling systems. (Krause P., Kralisch S., Flügel W.-A., Eds.), pp. 9-16, http://www.copernicus.org/EGU/adgeo/4/adgeo-4-9.pdf.

Hofman D. et al. (2005) EC Computerised Systems in the Field of Hydrological Dispersion Modelling and Aquatic Radioecological Research: State-of-the-art, End-user Experiences and Recommendations for Improvements. In: Evaluation and network of EC-Decision Support Systems in the field of hydrological dispersion models and of aquatic radioecological research. ENEA, RT/2005/49/PROT, Rome. (Monte L., Hofman D., Brittain J., Eds), pp. 203-322.

Monte L., van der Steen J., Bergstroem U., Gallego E., Brittain J., Håkanson L. (2000) The Project MOIRA: A Model-Based Computerised System for Management Support to Identify Optimal Remedial Strategies for Restoring Radionuclide Contaminated Aquatic Ecosystems and Drainage Areas. Final Report. Ente per le Nuove Tecnologie, l'Energia e l'Ambiente (ENEA), RT/AMB/2000/13, Rome.

Monte L., Kozhouharov V., Zheleznyak M., Kryshev I., Voitsekhovitch O., Brittain J., Gallego E., Håkanson L. (2002) Implementing Computerised Methodologies to Evaluate the Effectiveness of Countermeasures for Restoring Radionuclide Contaminated Fresh Water Ecosystems. COMETES Project. Final Report. Ente per le Nuove Tecnologie, l'Energia e l'Ambiente (ENEA), RT/AMB/2001/28, Rome.

Monte L., Brittain J.E., Håkanson L., Heling R., Smith J.T., Zheleznyak M. (2003) Review and assessment of models used to predict the fate of radionuclides in lakes, J. Environ. Radioact. 69, 177-205.

Monte L., Brittain J.E., Håkanson L., Smith J.T., van der Perk M. (2004) Review and assessment of models used to predict the migration of radionuclides from catchments, J. Environ. Radioact. 75, 83-103.

Monte L., Brittain J.E., Håkanson L., Smith J.T., Boyer P., Lepicard S. (2005) Review and assessment of models used to predict the migration of radionuclides through rivers, J. Environ. Radioact. 79, 273-296.

Monte L., Hofman D., Brittain J. (2005) Evaluation and network of EC-Decision Support Systems in the field of hydrological dispersion models and of aquatic radioecological research. ENEA, RT/2005/49/PROT, Rome.

Monte L., Brittain J.E., Gallego E., Håkanson L., Hofman D., Jiménez A. (2009) MOIRA-PLUS: A decision support system for the management of complex fresh water ecosystems contaminated by radionuclides and heavy metals, Computers and Geosciences, 35, 880-896.

Raskob W. (2007) European approach to nuclear and radiological emergency management and rehabilitation strategies (EURANOS), Kerntechnik 72, 179-182.

Ríos-Insúa S., Gallego E., Jiménez A., y Mateos A. (2006) A Multi-Attribute Decision Support System for selecting environmental intervention strategies for radionuclide contaminated freshwater ecosystems, Ecol. Modell. 196, 195-208.

Schulte E.-H., Kelly G.N., Jackson C.A. (2002) Decision support for emergency management and environmental restoration. European Commission, EUR19793, Luxembourg, 55 p. 